for taking too long to publish results of the HEGIS library surveys. One reason for the delay was that librarians were very slow to return completed questionnaires. In 1985, when the last HEGIS library survey was in process, Robert Wedgeworth, then Executive Director of ALA, and JoAn Segal, ACRL Executive Director, co-signed a letter sent to all academic library directors urging response. A good number called ALA to say that they had never received a form! This experience made us resolve to alert academic librarians next time the library survey form went out. If you don't get a copy by the end of September, contact the person on your campus responsible for responding to government surveys.

Once you have the survey, please fill it in completely and return it promptly to the indicated address. The sooner forms are returned, the sooner results can be published. ACRL and the ALA Office for Research are working with the NCES to get results out fast. You can help by returning your survey form as soon as possible. We are also working with NCES to improve the questionnaire. Please let us know what you think of the 1988 form.
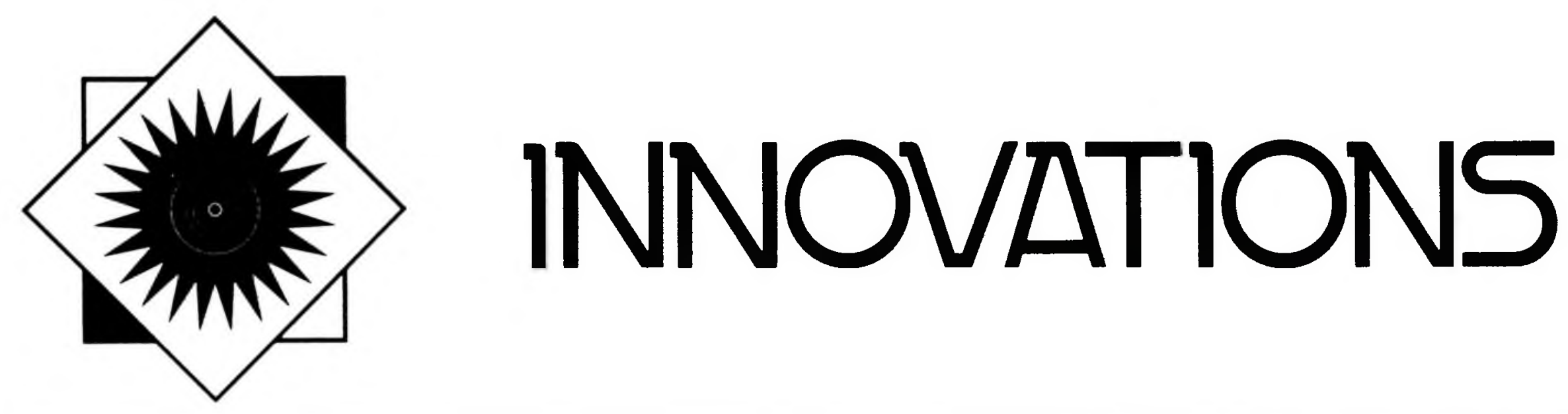

\title{
Faculty access to RLIN at New York University: RLG's research access project
}

\author{
By Melanie Dodson \\ Coordinator, Project Inform \\ Bobst Library, New York University
}

RLIN, the database of the Research Libraries Group, has entered the world of end user services through the Research Access Project (RAP), a pilot program involving eleven RLG institutions.

Initiated in early 1988, RAP provides faculty with RLIN searching accounts at a cost of $\$ 99$ for a ten hour block of search time. Each participating institution has adopted its own approach to subsidies, training, and selection of faculty. But all will contribute evaluative information about the project through a questionnaire developed in conjunction with the Public Services Committee of RLG.

At New York University, we have set up over forty library-subsidized RLIN/RAP accounts thus far for faculty and research staff-the largest group of accounts to date among the RAP institutions. RAP's enthusiastic reception at NYU is partly due to Project Inform, an initiative through which librarians at NYU are examining ways and means to utilize and integrate information systems throughout the campus. As part of Project Inform, we have introduced faculty to many online databases, including RLIN. Through these demonstra- tions, faculty see firsthand RLIN's capabilities and, by extension, the benefits of the Research Access Project.

Initially, we identified departments with faculty most likely to use RLIN as a research toolprimarily in the arts, humanities, and social sciences. Reference librarians and bibliographers also suggested specific faculty who use RLIN in the Library or who are involved in ongoing bibliographic research projects. These faculty were sent a letter and brochure describing the database and equipment needed to access it. From this targeted mailing of 100 , we received thirty-five requests for accounts from departments ranging from nursing to telecommunications and from cinema studies to Near Eastern languages. A month later, we distributed several more accounts following a general announcement in the Library's newsletter. While most accounts are for individual use, some are shared by faculty and graduate students within departments.

Librarians conducted training for participants during April and May. These one-hour sessions 
outlined database content, basic searching procedures, and interpretation of display formats, and also highlighted special databases and files such as the Eighteenth-Century Short Title Catalog and Archives and Manuscripts. Training packets for each participant included RLG instructional material, a mini-manual and quick reference sheet developed by NYU, and log-on procedures through Telenet. We distributed all account and password information at the time of training.

The majority of questions posed by users of remote databases typically relate to technical aspects of online searching, such as how to connect, download, and print. Our experience with RLIN is no exception. Given the variety of communications software packages available, we did not attempt to give RAP users a crash course in telecommunications. Rather, we provided assistance for packages used on campus, such as ProComm and Kermit and, where appropriate, referred users to the RLIN Information Center or their user manuals. In addition, as previously mentioned, we provided packets that contained detailed instructions on Telenet access and a Telenet help number.

The RLIN/RAP training sessions were an excellent opportunity for librarians to learn more about faculty research and for faculty to increase their awareness of library initiatives in the areas of database design and resource sharing. Further explanation of the MARC record structure was of special interest to several faculty involved in database construction, and created a common basis for understanding indexing and retrieval. The training sessions also gave us the opportunity to stress the utility of using NYU's online catalog, BobCat, in conjunction with RLIN for identifying local resources.

One of RLIN's strengths, of course, is the display of holdings information for member libraries. The breadth of the database and inclusion of location information within each record combine to create a powerful verification tool for faculty searchers. Because so many libraries within the metropolitan area contribute to the RLIN database, NYU faculty are able to identify a tremendous amount of locally available material from libraries such as Columbia, New York Public, the Metropolitan Museum, and a host of similar institutions.

Searching RLIN for themselves, faculty are introduced to the vast potential and importance of RLG's resource sharing programs.

An evaluation instrument, along with information collected by RLG, will provide extensive data on the relative ease or difficulty of searching the database, the usefulness of various files and special databases, and what barriers, if any, exist for end user access to RLIN. In addition, it will indicate impact on interlibrary loan, on-site referrals, and collection development activities, such as book purchase recommendations. Since the program has evolved differently among the RAP institutions, of interest will be the effect of various training approaches, attitudes toward the cost of searching, and satisfaction with the database. We will administer evaluations as participants complete their initial ten hours of connect time.

After only a few months, participants have expressed enthusiasm about using RLIN, due to its comprehensiveness as a database and its usefulness as a verification and location tool. As growing numbers of NYU faculty tap into RLIN, we are assessing our interlibrary loan program, considering document delivery options, and furthering our knowledge of the scholarly communication process. The Research Access Project is one of many initiatives in remote delivery of library services enabling us to realize the full potential of electronic access to information.

\title{
When closing a library is progress
}

\author{
By Rebecca Sturm \\ Head of Public Services \\ Northern Kentucky University
}

Like many other medium-sized academic libraries at the start of this decade, our university got caught up in the need to establish another campus, complete with a small library facility. Located in Covington, which was the original site of the University and about fifteen minutes from its present location, University College was established with a dean in the spring of 1983. The campus offers a variety of courses and special offerings and services, but no distinct academic programs. Faced with little start up money, slim hope of additional funds in the future and "no thank you" not an option, against our best instincts the library during the academic year of 1983-1984 set up what was called a "library referral center" for the new University College.

The Library Referral Center (afterwards referred to as the UCLRC) consisted of a small gen- 